\title{
Emergency department increased use of observation care for elderly medicare patients
}

\author{
Gelareh Z. Gabayan*1, Li-Jung Liang², Brian Doyle², David Yu-Chuang Huang ${ }^{2}$, Catherine A. Sarkisian ${ }^{4,5}$ \\ ${ }^{1}$ Department of Emergency Medicine, University of California, Los Angeles, California, United States \\ ${ }^{2}$ Divisions of General Internal Medicine and Health Services Research, David Geffen School of Medicine at UCLA, Los Angeles, \\ California, United States \\ ${ }^{3}$ Department of Medicine, Ohio State University, United States \\ ${ }^{4}$ Department of Medicine, University of California, Los Angeles, California, United States \\ ${ }^{5}$ Department of Medicine, Greater Los Angeles Veterans Affairs Healthcare System, Los Angeles, California, United States
}

Received: February 12, 2018

DOI: $10.5430 /$ jha.v7n3p9
Accepted: March 29, $2018 \quad$ Online Published: April 10, 2018

URL: https://doi.org/10.5430/jha.v7n3p9

\begin{abstract}
Background: Over the past decade, a growing number of older Medicare beneficiaries visit the emergency department (ED) and have been placed in observation care. We investigated and compared the prevalence and factors associated with patients age $\geq 65$ years with Medicare insurance who are placed in the hospital, observation care, or discharged following an ED visit.

Methods: We conducted a retrospective cohort study using data from a nationally representative 5\% sample of Medicare patients age $\geq 65$ years during the year 2013. We performed multiple generalized estimating equation (GEE) logistic regression analyses to assess the relationship between placement in a hospital vs. discharge, observation care vs. discharge, and observation care vs. admission.

Results: Of 537,455 Medicare beneficiaries age $\geq 65$ years who visited an ED in 2013, 48.0\% ( $\mathrm{N}=258,083)$ were discharged, $10.5 \%(\mathrm{~N}=56,184)$ placed in observation care, and $41.5 \%(\mathrm{~N}=223,188)$ were admitted to the inpatient service following the ED visit. The top 2 diagnoses associated with placement in the hospital vs. discharge were ischemic heart disease and renal disease. Patients with symptomatic diagnoses such as chest pain and dizziness were more likely to be placed in observation care following an ED visit as compared to admission to the hospital.

Conclusions: Compared to prior studies, we found a greater number of older Medicare ED patients placed in observation care and a lower number admitted to the hospital. Most common diagnoses of placement in observation care were symptom-based as compared to being admitted to the hospital which were disease-based.
\end{abstract}

Key Words: Observation, Emergency department, Medicare, Elderly patients, Older adults

\section{INTRODUCTION}

Over the past decade there has been an increase in the number of visits to the emergency department (ED), ${ }^{[1]}$ as well as an increase in the use of observation care patients receive. ${ }^{[2,3]}$ Guideline for observation care are driven by the institution that oversees the observation units. In the twenty first century, placement in the hospital from the ED could imply either placement in observation care or placement in an inpatient bed. This change or "shift" in care following an ED visit may be a result of the use of observation care to replace inpatient

\footnotetext{
${ }^{*}$ Correspondence: Gelareh Z. Gabayan; Email: Gelareh@gabayan.com; Address: Department of Emergency Medicine, University of California, Los Angeles, California. 
admission. ${ }^{[3-7]}$ Given these recent changes, it is important to understand the prevalence of outcomes following an ED visit and whether there is an increase in the use of observation care, but also to understand the factors associated with different outcomes following an ED visit.

Although there has been an increase in the rate of placement in the hospital following the $\mathrm{ED},{ }^{[8,9]}$ the associated factors and prevalence of placement in observation care is unknown. "Observation care" is a short-term (24-72 hrs) treatment and assessment provided to patients in an inpatient setting, either in the same original location or a different location by either the same provider who originally evaluated the patient in the ED or a different provider. ${ }^{[10]}$ There is no agreement as to the set time period to define observation care. The single guideline comes from the Centers for Medicare and Medicaid (CMS) who define observation care as care lasting less than 2 midnights. The idea of observation care dates back to Hippocrates who recommended to "observe" patients for a greater amount of time so that a condition is better understood. For Medicare beneficiaries, this care is billed as an outpatient visit. It is unknown when observation units started to occur in medicine.

There were 537,455 ED visits of patients with Medicare Insurance age $\geq 65$ years to any US hospital ED in 2013 in the analysis. The objective of the study was to evaluate the characteristics of patients seen in the ED who were discharged (to home or a non-acute care facility), placed in observation care, or placed in inpatient admission. Predictors of these outcomes following the ED visit were also assessed.

\section{Methods}

\subsection{Study design}

A retrospective cohort study of a 5\% nationally representative sample of Medicare patients who visited any US ED in 2013 was conducted. This study was approved by the IRB at the University of California at Los Angeles.

\subsection{Setting and selection of participants}

Participants were age $\geq 65$ years at the time of their ED visit. If participants had multiple ED visits, then only the first visit of the year was included in the analytic sample. Patients who had two or more ED claims on a given day were excluded as well as patients who died in the ED.

\subsection{Data sources}

Visit records used for the analysis were obtained from the CMS Outpatient File, the CMS Inpatient MEDPAR (Medicare Provider Analysis and Review) file, the Master Beneficiary File, and the Chronic Conditions file for 2013.

\subsection{Measures}

Patient comorbidities were obtained using the CMS Chronic Conditions file which was linked to the visit records using Claim ID. The CMS Chronic Conditions file contained information regarding the sum total of chronic conditions prior to the ED visit (0-27) and this total was used as a proxy for patient comorbidity. ED diagnoses were included based on a previously described algorithm created by the PI (GZG) of the study. ${ }^{[1-13]}$ In brief, the primary ICD-9 code for each ED visit was converted to a Multi-level Clinical Classification system (CCS) code using a cross-walk mapping process provided by the Healthcare Cost and Utilization Project (HCUP). ${ }^{[14]}$ A total of 39 categories were developed by the PI. Emergency Department visits, observation placement, inpatient admission, and use of a skilled nursing facility (SNF) were determined based on Revenue Center Codes as well as charges made to Medicare.

\subsection{Data analysis}

Patient characteristics (demographic and clinical) as well as discharge diagnoses were summarized for each of the three clinical outcomes following an ED visit (discharge, observation care, inpatient admission). In addition, both descriptive statistics and frequency distributions for continuous and categorical variables were generated.

Candidate factors included demographic characteristics, utilization of a SNF in 2013, patient comorbidities proxied by the number of CMS chronic conditions, and ED discharge diagnoses. Clinical Outcomes were modeled using a Generalized Estimating Equation (GEE) logistic regression. ${ }^{[15]}$ All hospitals were included as hospital-level random effects. All candidate factors were included as fixed effects.

The primary model examined the factors associated with placement in the hospital vs. discharge based on the entire study cohort. Two sub-group analyses evaluated the characteristics associated with placement in observation care vs. discharge (Model A) and placement in observation care vs. admission (Model B). Adjusted odds ratios (AOR) and 95\% confidence interval estimates were generated from these three analyses. The reference groups for all analyses were the following: age 65-69, female gender, weekday ED visit, single ED visit in 2013, never used a SNF, no chronic conditions, and ED discharge diagnosis of "Urinary Tract Infection".

\section{RESUltS}

\subsection{Sample characteristics}

Table 1 describes the characteristics and diagnoses of the cohort. Female to male patients visiting the ED had close to 2:1 ratio (female 337,252; male 200,203). As patients ages increased, there was a greater number admitted. Patients 
seen on weekends had a higher rate of being discharged. The diagnosis with the greatest percent $(92.8 \%)$ with a discharge home was "Other injuries" which includes a diagnosis of burns, wounds, and poisoning. Patients with renal disease had the highest frequency of admission from the $\operatorname{ED}(87.5 \%)$. There was no single diagnosis more likely to be placed in observation care.

Table 1. Characteristics of study subjects

\begin{tabular}{|c|c|c|c|c|}
\hline & 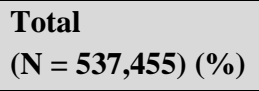 & $\begin{array}{l}\text { Discharged } \\
(\mathrm{N}=\mathbf{2 5 8 , 0 8 3 )}(\%)\end{array}$ & $\begin{array}{l}\text { Observation Care } \\
(N=56,184)(\%)\end{array}$ & $\begin{array}{l}\text { Admitted } \\
(\mathrm{N}=\mathbf{2 2 3}, 188)(\%)\end{array}$ \\
\hline \multicolumn{5}{|l|}{ Age at ER admission } \\
\hline - $65-69$ & $106,277(19.8)$ & $60,255(23.4)$ & $10,115(19.0)$ & $35,907(16.1)$ \\
\hline - $70-74$ & $98,546(18.3)$ & $51,176(19.8)$ & $9,975(17.7)$ & $37,395(16.7)$ \\
\hline - $75-79$ & $97,598(18.2)$ & $47,056(18.2)$ & $10,483(18.7)$ & $40,059(18.0)$ \\
\hline - $80+$ & $235,034(43.7)$ & $99,596(38.6)$ & $25,611(45.6)$ & $109,827(49.2)$ \\
\hline \multicolumn{5}{|l|}{ Gender } \\
\hline - Female & $337,252(62.7)$ & $165,018(63.9)$ & $35,874(63.9)$ & $136,360(61.1)$ \\
\hline - Male & $200,203(37.3)$ & $93,065(36.1)$ & $20,310(36.1)$ & $86,828(38.9)$ \\
\hline \multicolumn{5}{|l|}{ Race/Ethnicity } \\
\hline - White & $454,566(84.6)$ & $218,299(84.6)$ & $48,383(86.1)$ & $187,884(84.2)$ \\
\hline - Black & $53,154(9.9)$ & $25,509(9.9)$ & $5,126(9.1)$ & $22,519(10.1)$ \\
\hline - Asian & $8,077(1.5)$ & $3,647(1.4)$ & $795(1.4)$ & $3,635(1.6)$ \\
\hline - Hispanic & $11,321(2.1)$ & $5,340(2.1)$ & 915 (1.6) & $5,066(2.3)$ \\
\hline - North American N & $2,286(0.4)$ & $1,302(0.5)$ & $221(0.4)$ & $763(0.3)$ \\
\hline \multicolumn{5}{|l|}{ Day of week of service } \\
\hline - Weekday & $388,286(72.2)$ & $181,696(70.4)$ & $42,084(74.9)$ & $164,506(73.7)$ \\
\hline - Weekend & $149,169(27.8)$ & 76,387 (29.6) & $14,100(25.1)$ & $58,682(26.3)$ \\
\hline \multicolumn{5}{|l|}{ Comorbidity } \\
\hline - Cataract & $354,897(66.0)$ & $179,154(69.4)$ & $39,451(70.2)$ & $136,292(61.1)$ \\
\hline - Ischemic Heart Disease & $309,377(57.6)$ & $143,975(55.8)$ & $35,797(63.7)$ & $129,605(58.1)$ \\
\hline - Rheumatoid Arthritis/Osteoarthritis & $318,304(59.2)$ & $161,808(62.7)$ & $35,772(63.7)$ & $120,724(54.1)$ \\
\hline - Anemia & $322,183(59.9)$ & $152,815(59.2)$ & $35,289(62.8)$ & $134,079(60.1)$ \\
\hline - Hyperlipidemia & $404,640(75.3)$ & $203,773(79.0)$ & $44,918(79.9)$ & $155,949(69.9)$ \\
\hline - Hypertension & $440,855(82.0)$ & $217,886(84.4)$ & $48,472(86.3)$ & $174,497(78.2)$ \\
\hline \multicolumn{5}{|l|}{ Diagnosis } \\
\hline - Other Injuries & $47,263(8.8)$ & $43,850(17.0)$ & $1,358(2.4)$ & $2,055(0.9)$ \\
\hline - GI System Diseases & $46,033(8.6)$ & $16,240(6.3)$ & $4,303(7.7)$ & $25,490(11.4)$ \\
\hline - Minor Injuries & $41,602(7.7)$ & $23,318(9.0)$ & $2,198(3.9)$ & $16,086(7.2)$ \\
\hline $\begin{array}{l}\text { Diseases of the musculoskeletal } \\
\text { system skin and connective tissue }\end{array}$ & $32,456(6.0)$ & $25,930(10.0)$ & $2,329(4.1)$ & $4,197(1.9)$ \\
\hline - Chest pain & $22,849(4.3)$ & $9,189(3.6)$ & $10,378(18.5)$ & $3,282(1.5)$ \\
\hline - Dizziness vertigo and syncope & $20,431(3.8)$ & $11,730(4.5)$ & $5,073(9.0)$ & $3,628(1.6)$ \\
\hline $\begin{array}{l}\text { - Other Infectious and Parasitic } \\
\text { Diseases }\end{array}$ & $20,563(3.8)$ & $2,466(1.0)$ & $839(1.5)$ & $17,258(7.7)$ \\
\hline - Urinary Tract Infection & $18,741(3.5)$ & $9,877(3.8)$ & $1,566(2.8)$ & $7,298(3.3)$ \\
\hline - Dysrythmias and condition disorders & $18,735(3.5)$ & $4,983(1.9)$ & $2,475(4.4)$ & $11,277(5.1)$ \\
\hline - Cerebrovascular Disease & $18,298(3.4)$ & $1,681(0.7)$ & $2,385(4.2)$ & $14,232(6.4)$ \\
\hline
\end{tabular}

Note. Column percentages are presented. Comorbidities in less than $50 \%$ of the study cohort are not shown. All the comorbidities of the study cohort are listed in the supplementary material. The top ten diagnoses are listed. All diagnoses of the study cohort are listed in the supplementary material 


\subsection{Main results}

Among the 537,455 patients who visited a US ED in 2013, $48.0 \%(\mathrm{~N}=258,083)$ were discharged, $10.5 \%(\mathrm{~N}=56,184)$ placed in observation care, and $41.5 \%(\mathrm{~N}=223,188)$ were admitted to the inpatient service (see Figure 1). Table 2 presents the results from the main regression model for the bivariate outcome of staying in the hospital (observation care or inpatient admission) vs. discharge. Age was associated with an increased odds of hospital stay (range of AORs: 1.261.89). Compared to non-Hispanic whites, other ethnicities had a lower odds of staying in the hospital (range of ORs: 0.87-0.93). Patients with an ED visit on the weekend also had a lower odds of being placed in the hospital (OR 0.88, 95\% CI 0.87-0.89). In addition, patients placed in a SNF had a greater odds of being placed in the hospital (AOR 2.99, 95\% CI 2.93-3.05). In comparison to patients with a diagnosis of Urinary Tract Infection, the top three diagnoses associated with being placed in the hospital were Renal Disease (AOR 19.3, 95\% CI 17.8-20.9), Ischemic heart disease (AOR 16.5, 95\% CI 15.4-17.6), and non-atherosclerotic Heart Disease (AOR 11.4, 95\% CI 10.3-12.6).

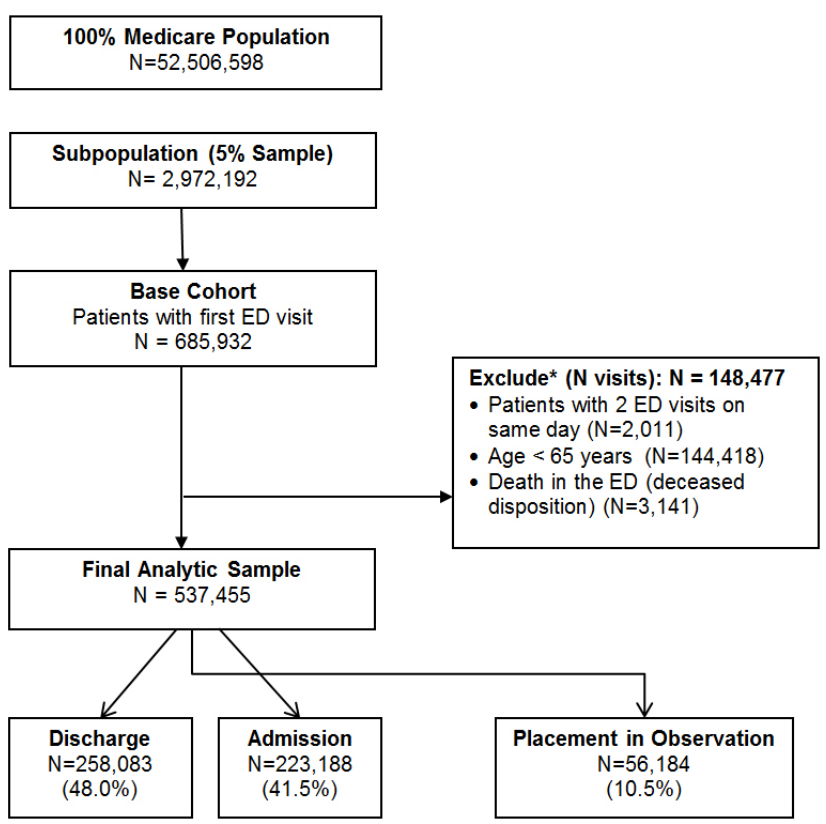

Figure 1. Study cohort

Table 3 presents the regression results of the subgroup analyses of being placed in observation care vs. discharge (Model A) or observation care vs. admission (Model B). The model of being placed in observation care vs. discharge (Model A) showed that older age or non-Hispanic white race was asso- ciated with an increased odds of being placed in observation care, which is similar to the findings in the main analysis (see Table 2). Patients using a SNF were almost two times more likely to be placed in observation (AOR 1.87, 95\% CI 1.81-1.93). The top two diagnoses in Model A (observation vs. discharge) were similar to the findings of Table 2: ischemic heart disease (AOR 19.2, 95\% CI 17.3-21.9), renal disease (AOR 12.9, 95\% CI 11.2-14.8), cerebrovascular disease (AOR 8.58, 95\% CI 7.86-9.37).

Model B presented in Table 3 exhibits that patients who were in a SNF in 2013 were less likely to be placed in observation vs. admission (AOR 0.65, 95\% CI 0.64-0.67). The diagnoses with the greatest odds of the observation outcome were complaints of symptoms such as chest pain (AOR 12.6, 95\% CI 11.7-13.6) and dizziness (AOR 5.94, 95\% CI 5.53-6.39). Patients with disease based diagnoses such as pneumonia (AOR $0.38,95 \%$ CI $0.35-0.41$ ) and congestive heart failure (CHF) (AOR 0.50, 95\% CI 0.47-0.54) had lower likelihood of placement in observation care.

\section{Discussion}

EDs are increasingly used as a usual source of care, ${ }^{[1]}$ especially by older adults. Outcomes following an ED visit have also changed. A greater percent of ED visits result in placement in observation care ${ }^{[3]}$ requiring a better current understanding of the factors associated with all outcomes following ED care. Compared to prior literature, ${ }^{[3]}$ our study found that of Medicare patients seen in the ED, $41.5 \%$ of patients are admitted to the hospital and $10.5 \%$ are placed in observation care. We found older non-Hispanic white males and patients with renal disease to have the highest odds of being placed in the hospital while symptom-based diagnoses to have the greatest odds of placement in observation care.

Older non-Hispanic white males had the greatest odds of being placed in the hospital. The requirement of a greater acuity of care following an ED visit is a marker of a more concerning presentation. This finding is consistent with our prior studies showing that older non-Hispanic white males were more likely to suffer poor outcomes following discharge from the ED. ${ }^{[1,13,16-18]}$ As expected, age has been found to be a marker of a greater disease burden as older adults are more likely to accrue comorbidities. ${ }^{[19,20]}$ In numerous studies, men have often been found to have a greater incidence of disease then women in these population-based analyses. Overall, we are uncertain as to why non-Hispanic white ethnicity was associated with a greater chance of being placed in the hospital. 
Table 2. GEE logistic regression results for being placed in the hospital and observation

\begin{tabular}{|c|c|c|}
\hline Patient Characteristics & Odds Ratio (95\% CI) & $p$-value \\
\hline \multicolumn{3}{|l|}{ Age $(\mathrm{REF}=65-69)$} \\
\hline - $70-74$ & $1.26(1.23-1.28)$ & $<.0001$ \\
\hline - $75-79$ & $1.51(1.48-1.55)$ & $<.0001$ \\
\hline - $80+$ & $1.89(1.85-1.94)$ & $<.0001$ \\
\hline \multicolumn{3}{|l|}{ Gender } \\
\hline - Male vs. Female & $1.06(1.05-1.08)$ & $<.0001$ \\
\hline \multicolumn{3}{|l|}{ Race/Ethnicity (REF = White) } \\
\hline - Black & $0.89(0.87-0.92)$ & $<.0001$ \\
\hline - Others & $0.89(0.85-0.93)$ & $<.0001$ \\
\hline - Asian/PI & $0.93(0.88-0.99)$ & .0233 \\
\hline - Hispanic & $0.87(0.83-0.91)$ & $<.0001$ \\
\hline \multicolumn{3}{|l|}{ Day of week of service } \\
\hline - Weekend vs. Weekday & $0.88(0.87-0.89)$ & $<.0001$ \\
\hline \multicolumn{3}{|l|}{ Total number of ER visits in 2013} \\
\hline - Multiple vs. Single & $0.86(0.85-0.87)$ & $<.0001$ \\
\hline \multicolumn{3}{|l|}{ Ever used SNF services in 2013} \\
\hline - Yes vs. No & $2.99(2.93-3.05)$ & $<.0001$ \\
\hline - Number of chronic conditions* ${ }^{*}$ & $0.96(0.96-0.96)$ & $<.0001$ \\
\hline \multicolumn{3}{|l|}{ ED Discharge Diagnosis (REF = Urinary Tract Infection) } \\
\hline - Renal Disease & $19.25(17.76-20.88)$ & $<.0001$ \\
\hline - Ischemic Heart Disease & $16.48(15.41-17.62)$ & $<.0001$ \\
\hline - Non-atherosclerotic Heart Disease & $11.38(10.25-12.63)$ & $<.0001$ \\
\hline - $\mathrm{CHF}$ & $10.02(9.47-10.61)$ & $<.0001$ \\
\hline - Cerebrovascular Disease & $9.21(8.72-9.72)$ & $<.0001$ \\
\hline - Neoplasms & $8.21(7.54-8.94)$ & $<.0001$ \\
\hline - Non-infectious Lung Disease & $7.57(6.92-8.29)$ & $<.0001$ \\
\hline - Other Infectious and Parasitic; Diseases: Meningitis, infective arthritis, Bacterial, Mycoses, Viral & $7.1(6.72-7.49)$ & $<.0001$ \\
\hline - Intestinal Infection & $5.98(5.46-6.55)$ & $<.0001$ \\
\hline - Pneumonia & $5.84(5.56-6.13)$ & $<.0001$ \\
\hline - Diseases of the blood & $4.8(4.44-5.19)$ & $<.0001$ \\
\hline - Dysrhythmias & $3.26(3.11-3.42)$ & $<.0001$ \\
\hline - Asthma & $2.41(2.23-2.60)$ & $<.0001$ \\
\hline - Complications and Adverse events & $2.41(2.28-2.55)$ & $<.0001$ \\
\hline - Circulatory Disorders & $2.31(2.19-2.43)$ & $<.0001$ \\
\hline - Major Injuries & $2.29(2.13-2.47)$ & $<.0001$ \\
\hline - GI system Diseases & $2.25(2.17-2.34)$ & $<.0001$ \\
\hline - $\mathrm{COPD}$ & $2.21(2.11-2.31)$ & $<.0001$ \\
\hline - Symptoms: Chest Pain & $2.12(2.02-2.23)$ & $<.0001$ \\
\hline - Endocrine, nutritional, immunity and metabolic disorders & $1.8(1.71-1.89)$ & $<.0001$ \\
\hline - Diabetes Mellitus & $1.53(1.44-1.63)$ & $<.0001$ \\
\hline - Congenital Diseases & $1.2(0.84-1.72)$ & .3243 \\
\hline - Skin and Subcutaneous infections & $1.08(1.02-1.14)$ & .0053 \\
\hline - Mental illness & $1.04(0.98-1.11)$ & .1726 \\
\hline - Symptoms: Dizziness, Vertigo and Syncope & $0.94(0.89-0.98)$ & .004 \\
\hline - Hypertension & $0.86(0.81-0.91)$ & $<.0001$ \\
\hline - Nervous system Disorders & $0.81(0.77-0.86)$ & $<.0001$ \\
\hline - Other Respiratory Diseases & $0.79(0.75-0.83)$ & $<.0001$ \\
\hline - Minor Injuries & $0.77(0.74-0.80)$ & $<.0001$ \\
\hline - Upper Respiratory Infection & $0.49(0.46-0.52)$ & $<.0001$ \\
\hline - Other Renal and GI Diseases & $0.41(0.38-0.43)$ & $<.0001$ \\
\hline - Other Residual Codes & $0.4(0.38-0.43)$ & $<.0001$ \\
\hline - Symptoms: Others & $0.33(0.31-0.34)$ & $<.0001$ \\
\hline - Diseases of the musculoskeletal system, skin and connective tissue & $0.29(0.28-0.30)$ & $<.0001$ \\
\hline - Symptoms: Abdominal Pain & $0.23(0.21-0.24)$ & $<.0001$ \\
\hline - Symptoms: Headache & $0.15(0.13-0.17)$ & $<.0001$ \\
\hline - Other Injuries & $0.09(0.08-0.09)$ & $<.0001$ \\
\hline
\end{tabular}

Note. GEE logistic regression analysis of odds of being placed in hospital (observation care or inpatient admission vs. discharge. Reference category for discharge diagnoses is "urinary tract infection". Top ten diagnoses presented. All diagnoses presented in supplementary material." Based on the CMS Chronic Conditions 
Table 3. GEE logistic regression for being placed in observation

\begin{tabular}{|c|c|c|c|c|}
\hline \multirow[t]{2}{*}{ Characteristics } & \multicolumn{2}{|c|}{$\begin{array}{l}\text { Observation vs. Discharge } \\
\text { (Model A; N = 314,267) }\end{array}$} & \multicolumn{2}{|c|}{$\begin{array}{l}\text { Observation vs. Admission } \\
\text { (Model B; } N=\mathbf{2 7 9 , 3 7 2 )}\end{array}$} \\
\hline & Odds Ratio (95\% CI) & $p$ & Odds Ratio (95\% CI) & $p$ \\
\hline \multicolumn{5}{|l|}{ Patient Characteristics } \\
\hline \multicolumn{5}{|l|}{ Age $(\mathrm{REF}=65-69)$} \\
\hline - $70-74$ & $1.13(1.09-1.17)$ & $<.0001$ & $0.91(0.88-0.94)$ & $<.0001$ \\
\hline - $75-79$ & $1.29(1.24-1.33)$ & $<.0001$ & $0.88(0.85-0.91)$ & $<.0001$ \\
\hline - $80+$ & $1.54(1.49-1.60)$ & $<.0001$ & $0.84(0.82-0.87)$ & $<.0001$ \\
\hline - Male vs. Female & $0.99(0.97-1.01)$ & .3875 & $0.92(0.91-0.94)$ & $<.0001$ \\
\hline \multicolumn{5}{|l|}{ Race/Ethnicity (REF = Non-Hispanic White) } \\
\hline - Black & $0.90(0.86-0.94)$ & $<.0001$ & $0.94(0.91-0.97)$ & .0008 \\
\hline - Others & $0.91(0.84-0.98)$ & .0131 & $0.97(0.91-1.04)$ & .4244 \\
\hline - Asian/PI & $0.95(0.87-1.04)$ & .2918 & $0.97(0.90-1.05)$ & .5089 \\
\hline - Hispanic & $0.82(0.76-0.88)$ & $<.0001$ & $0.85(0.79-0.91)$ & $<.0001$ \\
\hline \multicolumn{5}{|l|}{ Day of week of service } \\
\hline \multicolumn{5}{|l|}{ Total number of ER visits in 2013} \\
\hline - Multiple vs. Single & $0.87(0.85-0.89)$ & $<.0001$ & $0.99(0.97-1.01)$ & .1899 \\
\hline \multicolumn{5}{|l|}{ Ever used SNF services in 2013} \\
\hline - Yes vs. No & $1.87(1.81-1.93)$ & $<.0001$ & $0.65(0.64-0.67)$ & $<.0001$ \\
\hline - Number of chronic conditions & $1.00(1.00-1.01)$ & .1543 & $1.05(1.04-1.05)$ & $<.0001$ \\
\hline \multicolumn{5}{|l|}{ ED Discharge Diagnosis (REF = Urinary Tract Infection) } \\
\hline - Ischemic Heart Disease & $19.15(17.31-21.19)$ & $<.0001$ & $0.98(0.92-1.05)$ & 6099 \\
\hline - Renal Disease & $12.91(11.24-14.82)$ & $<.0001$ & $0.53(0.49-0.57)$ & $<.0001$ \\
\hline - Cerebrovascular Disease & $8.58(7.86-9.37)$ & $<.0001$ & $0.84(0.79-0.90)$ & $<.0001$ \\
\hline - Symptoms: Chest Pain & $7.89(7.36-8.47)$ & $<.0001$ & $12.58(11.67-13.57)$ & $<.0001$ \\
\hline - Non-atherosclerotic Heart Disease & $6.96(5.87-8.26)$ & $<.0001$ & $0.54(0.49-0.60)$ & $<.0001$ \\
\hline - Intestinal Infection & $6.2(5.40-7.13)$ & $<.0001$ & $0.99(0.89-1.11)$ & .8908 \\
\hline - $\mathrm{CHF}$ & $5.69(5.17-6.27)$ & $<.0001$ & $0.5(0.47-0.54)$ & $<.0001$ \\
\hline - Neoplasms & $5.01(4.42-5.68)$ & $<.0001$ & $0.56(0.52-0.61)$ & $<.0001$ \\
\hline - Dysrhythmias & $3.31(3.07-3.57)$ & $<.0001$ & $1(0.94-1.07)$ & .9144 \\
\hline - Symptoms: Dizziness, Vertigo and Syncope & $2.87(2.68-3.07)$ & $<.0001$ & $5.94(5.53-6.39)$ & $<.0001$ \\
\hline - Pneumonia & $2.54(2.33-2.77)$ & $<.0001$ & $0.38(0.35-0.41)$ & $<.0001$ \\
\hline - Endocrine, nutritional, immunity and metabolic disorders & $2.53(2.34-2.73)$ & $<.0001$ & $1.6(1.50-1.72)$ & $<.0001$ \\
\hline - Asthma & $2.34(2.06-2.66)$ & $<.0001$ & $1.02(0.92-1.13)$ & .7485 \\
\hline - Circulatory Disorders & $2.21(2.01-2.43)$ & $<.0001$ & $0.99(0.92-1.07)$ & .8726 \\
\hline $\begin{array}{l}\text { - Other Infectious and Parasitic; Diseases: Meningitis, infective } \\
\text { arthritis, Bacterial, Mycoses, Viral }\end{array}$ & $2.2(2.00-2.43)$ & $<.0001$ & $0.28(0.26-0.30)$ & $<.0001$ \\
\hline - GI system Diseases & $1.77(1.66-1.89)$ & $<.0001$ & $0.79(0.75-0.84)$ & $<.0001$ \\
\hline - Complications and Adverse events & $1.76(1.58-1.95)$ & $<.0001$ & $0.75(0.69-0.82)$ & $<.0001$ \\
\hline - $\mathrm{COPD}$ & $1.68(1.55-1.82)$ & $<.0001$ & $0.75(0.69-0.80)$ & $<.0001$ \\
\hline - Congenital Diseases & $1.51(0.85-2.68)$ & .1575 & $1.43(0.84-2.45)$ & .1906 \\
\hline - Diabetes Mellitus & $1.46(1.31-1.63)$ & $<.0001$ & $1.06(0.96-1.16)$ & .2427 \\
\hline - Major Injuries & $1.31(1.12-1.52)$ & .0005 & $0.56(0.50-0.63)$ & $<.0001$ \\
\hline - Nervous system Disorders & $1.3(1.20-1.41)$ & $<.0001$ & $1.86(1.73-2.00)$ & $<.0001$ \\
\hline - Hypertension & $1.13(1.03-1.24)$ & .0099 & $1.49(1.37-1.62)$ & $<.0001$ \\
\hline - Mental illness & $1.03(0.93-1.14)$ & .5677 & $1.01(0.92-1.12)$ & .7737 \\
\hline - Other Residual Codes & $1.02(0.93-1.12)$ & .6301 & $3.61(3.25-4.01)$ & $<.0001$ \\
\hline - Symptoms: Others & $0.77(0.71-0.83)$ & $<.0001$ & $3.35(3.06-3.66)$ & $<.0001$ \\
\hline - Skin and Subcutaneous infections & $0.73(0.66-0.81)$ & $<.0001$ & $0.67(0.61-0.74)$ & $<.0001$ \\
\hline - Other Respiratory Diseases & $0.73(0.67-0.80)$ & $<.0001$ & $0.93(0.86-1.01)$ & .0927 \\
\hline - Minor Injuries & $0.6(0.56-0.65)$ & $<.0001$ & $0.74(0.69-0.79)$ & $<.0001$ \\
\hline - Symptoms: Abdominal Pain & $0.6(0.55-0.67)$ & $<.0001$ & $4.02(3.59-4.51)$ & $<.0001$ \\
\hline $\begin{array}{l}\text { - Diseases of the musculoskeletal system, skin and connective } \\
\text { tissue }\end{array}$ & $0.59(0.55-0.63)$ & $<.0001$ & $2.66(2.49-2.86)$ & $<.0001$ \\
\hline - Other Renal and GI Diseases & $0.57(0.52-0.63)$ & $<.0001$ & $1.57(1.42-1.73)$ & $<.0001$ \\
\hline - Upper Respiratory Infection & $0.55(0.50-0.60)$ & $<.0001$ & $1.15(1.05-1.26)$ & .0024 \\
\hline - Symptoms: Headache & $0.43(0.37-0.50)$ & $<.0001$ & $4.29(3.54-5.21)$ & $<.0001$ \\
\hline - Other Injuries & $0.2(0.18-0.21)$ & $<.0001$ & $2.85(2.61-3.11)$ & $<.0001$ \\
\hline
\end{tabular}

Note. Reference category for discharge diagnosis is "urinary tract infection". Top ten diagnoses presented. The supplementary material section contains all diagnoses 
In addition, despite controlling for chronic conditions, patients with renal disease which includes a diagnosis of nephritis, nephrosis, renal sclerosis, acute renal failure, and chronic renal failure had the greatest odds of being placed in the hospital. This result is similar to our prior findings ${ }^{[11,13,17,18]}$ that suggest patients with renal disease may have underlying conditions that result in poor outcomes. This is also consistent with prior literature that has found patients with renal disease to be a worldwide public health problem, costly to the healthcare system and considered to be the "highest risk group". ${ }^{[21]}$ Our findings in this analysis suggest that extra caution be taken when evaluating patients with renal disease in the ED.

As makes clinical sense, symptom-based diagnoses such as chest pain had the greatest odds of being placed in observation care. Prior to the use of observation care, "chest pain units" were described in the literature as a means of placing patients in the hospital to prevent admission while decreasing the potential cost of missing a myocardial infarction. ${ }^{[22,23]}$ Although there has been question as to the utility of observation care, ${ }^{[3]}$ prior studies have shown that observation care is a proper treatment plan when a patients requires further evaluation. ${ }^{[14,23]}$ Our study confirms the finding that symptom-based diagnoses or diagnoses that do not have an obvious source of disease are more likely to be placed in observation care rather than admission.

We were able to identify the findings of the analyses based on the use of ICD-9 codes. ICD-9 codes have served as the foundation of numerous prior studies and population-based analyses. ${ }^{[24]}$ In 2014 ICD-10 codes were introduced and then mandated to be used by all providers in $2015 .{ }^{[25]}$ There are five times the number of ICD-10 codes as compared to ICD-9 codes. ICD-10 codes have more granularity and specificity. While the coding has changed, the practice of emergency medicine has not. The ED is a fast-paced environment in which providers are limited in the amount of time they can dedicate to the diagnosis and treatment of patients. Instead of dedicating more time to provide more detailed ICD-10 codes, emergency providers may be inclined to use codes that are less detailed within the ICD-10 coding system. Instead of resulting in greater specificity, the ICD-10 codes may result in less detailed coding as well.

\section{Limitations}

The study has several potential limitations. First, the analysis is based on data derived from claim ID, billing data, and ICD-9 codes, which are limited in that they are retrospective and can reflect incomplete coding. Second, a majority of patients who use Medicare insurance do not visit Federal hospitals so these findings are not generalizable to Federal facilities. ${ }^{[26]}$ Third, the analysis did not include information from prior year ED visits as that would require use of data from a prior year that the team did not have. Also, the files lack clinical variables that evaluate functional impairment, social support, transitions in care and health literacy. In addition, the type and location of observation care a patient receives is unknown and is specific to a hospital and/or medical system. Finally, the data is several years old as a result of the time it took to acquire (2 years), link and clean the files ( 2 years). Despite these limitations, this study provides important information regarding Medicare beneficiaries that utilize EDs.

\section{Conclusions}

The findings of this analysis confirm the changing climate of outcomes of patients following an ED visit and the greater likelihood of symptom-based diagnoses to result in observation services. The analysis also found older white males and patients with renal disease to have the highest odds of being placed in the hospital. Compared to prior studies, a greater number of older Medicare ED patients were placed in observation care as compared to being admitted to the hospital. The findings also identified the diagnoses with the greatest odds of being placed in the hospital or observation care.

\section{FUNDING AND SUPPORT}

This research and Dr. Gabayan were supported by the National Institute on Aging Grant for Early Medical/Surgical Specialists Transition to Aging Research Grant (GEMSSTAR R03AG047862-01) and the American Geriatric Society Jahnigen Award. Dr. Sarkisian is currently supported by the National Institute on Aging (1K24AG047899-01). The content is solely the responsibility of the authors and does not necessarily represent the official views of the NIH. The funding organizations did not have a role in the design and conduct of the study; management, analysis, and interpretation of the data; and preparation, review, or approval of the manuscript.

\section{AUTHOR CONTRIBUTION}

GZG conceived the study and obtained funding. CAS, LL and BD aided in the design of the study and CAS supervised the conduct of the study. LL and DYH managed the data, provided statistical advice, and conducted analyses. GZG drafted the manuscript and all authors contributed substantially to its revision. GZG takes responsibility for the paper as a whole.

\section{CONFLiCTS OF InTEREST Disclosure}

The authors declare they have no conflicts of interest. 


\section{REFERENCES}

[1] Tang N, Stein J, Hsia RY, et al. Trends and characteristics of US emergency department visits, 1997-2007. JAMA. Aug 11 2010; 304(6): 664-670. PMid: 20699458. https://doi.org/10.1001/jama. 2 010.1112

[2] Venkatesh AK, Geisler BP, Gibson CJJ, et al. Use of observation care in US emergency departments, 2001 to 2008. PLoS One. 2011; 6(9): e24326. PMid: 21935398. https://doi.org/10.1371/journa 1. pone. 0024326

[3] Feng Z, Wright B, Mor V. Sharp rise in Medicare enrollees being held in hospitals for observation raises concerns about causes and consequences. Health Aff (Millwood). Jun 2012; 31(6): 1251-1259. PMid: 22665837. https://doi.org/10.1377/hlthaff . 2012.0129

[4] Cafardi SG, Pines JM, Deb P, et al. Increased observation services in Medicare beneficiaries with chest pain. Am J Emerg Med. Jan 2016; 34(1): 16-19. PMid: 26490388. https : //doi .org/10.101 6/j.ajem. 2015.08.049

[5] Baugh CW, Venkatesh AK, Bohan JS. Emergency department observation units: A clinical and financial benefit for hospitals. Health Care Manage Rev. Jan-Mar 2011; 36(1): 28-37. PMid: 21157228. https://doi.org/10.1097/HMR . Ob013e3181f3c035

[6] Baugh CW, Liang LJ, Probst MA, et al. National cost savings from observation unit management of syncope. Acad Emerg Med. Aug 2015; 22(8): 934-941. PMid: 26204970. https ://doi.org/10.1 111 /acem. 12720

[7] Baugh CW, Venkatesh AK, Hilton JA, et al. Making greater use of dedicated hospital observation units for many short-stay patients could save \$3.1 billion a year. Health Aff (Millwood). Oct 2012; 31(10): 2314-2323. PMid: 23019185. https ://doi .org/10.137 7/hlthaff.2011.0926

[8] Steinmiller J, Routasalo P, Suominen T. Older people in the emergency department: a literature review. Int J Older People Nurs. Dec 2015; 10(4): 284-305. PMid: 26183883. https ://doi.org/10.1 111/opn. 12090

[9] Aminzadeh F, Dalziel WB. Older adults in the emergency department: a systematic review of patterns of use, adverse outcomes, and effectiveness of interventions. Ann Emerg Med. Mar 2002; 39(3): 238-247. PMid: 11867975. https ://doi.org/10.1067/mem. 20 02.121523

[10] Tavenner M. Office of Inspector General. Memorandum report: hospitals' use of observation stays and short inpatient stays for Medicare beneficiaries.

[11] Gabayan GZ, Derose SF, Asch SM, et al. Patterns and predictors of short-term death after emergency department discharge. Ann Emerg Med. Dec 2011; 58(6): 551-558. PMid: 21802775. https://doi.org/10.1016/j .annemergmed.2011.07.001

[12] Gabayan GZ, Hsia RY, Zingmond D, et al. Factors Associated with Short-Term Bounce-back Admissions Following Emergency Department Discharge. Ann Emerg Med. 2012.

[13] Gabayan GZ, Sarkisian CA, Liang LJ, et al. Predictors of admission after emergency department discharge in older adults. J Am Geriatr Soc. Jan 2015; 63(1): 39-45. PMid: 25537073. https: //doi.org/10.1111/jgs.13185
[14] Beta Classifications Software (CCS) for Mortality Reporting. Available from: http://www.hcup-us.ahrq.gov/toolssoftware /icd_10/ccs_icd_10.jsp

[15] Diggie PJ, Heagerty P, Liang KY, et al. Analysis of Longitudinal Data. Second Edition ed. Oxford: Oxford University Press; 2002.

[16] Gabayan GZ, Derose SF, Asch SM, et al. Predictors of short-term (seven-day) cardiac outcomes after emergency department visit for syncope. Am J Cardiol. Jan 1 2010; 105(1): 82-86. PMid: 20102895. https://doi.org/10.1016/j.amjcard.2009.08.654

[17] Gabayan GZ, Sun BC, Asch SM, et al. Qualitative factors in patients who die shortly after emergency department discharge. Acad Emerg Med. Aug 2013; 20(8): 778-785. PMid: 24033620. https : //doi.org/10.1111/acem. 12181

[18] Gabayan GZ, Asch SM, Hsia RY, et al. Factors Associated With Short-Term Bounce-Back Admissions After Emergency Department Discharge. Ann Emerg Med. Feb 25 2013. https ://doi .org/10 .1016/j . annemergmed.2013.01.017

[19] Fried L, Kronmal R, Newman A, et al. Risk factors for 5-year mortality in older adults: the Cardiovascular Health. JAMA. 1998; 279(8): 585-592. PMid: 9486752. https://doi.org/10.1001/jama.2 79.8 .585

[20] Ganguli M, Dodge HH, Mulsant BH. Rates and predictors of mortality in an aging, rural, community-based cohort: the role of depression. Arch Gen Psychiatry. Nov 2002; 59(11): 10461052. PMid: 12418938. https://doi.org/10.1001/archpsyc .59 .11 .1046

[21] Sarnak MJ, Levey AS, Schoolwerth AC, et al. Kidney disease as a risk factor for development of cardiovascular disease: a statement from the American Heart Association Councils on Kidney in Cardiovascular Disease, High Blood Pressure Research, Clinical Cardiology, and Epidemiology and Prevention. Circulation. Oct 28 2003; 108(17): 2154-2169. PMid: 14581387. https://doi.org/10.1161/01.C IR. 0000095676.90936 .80

[22] Lee TH, Goldman L. Evaluation of the patient with acute chest pain. N Engl J Med. Apr 20 2000; 342(16): 1187-1195. PMid: 10770985. https://doi.org/10.1056/NEJM200004203421607

[23] Clancy M. Chest pain units. BMJ. Jul 20 2002; 325(7356): 116117. PMid: 12130592 . https://doi.org/10.1136/bmj.325.73 56.116

[24] Owens PL, Barrett ML, Gibson TB, et al. Emergency department care in the United States: a profile of national data sources. Ann Emerg Med. Aug 2010; 56(2): 150-165. PMid: 20074834. https : //doi.org/10.1016/j.annemergmed.2009.11.022

[25] International Classification of Diseases, Tenth Revision. Accessed May 17, 2017. Available from: https://www.cdc.gov/nchs/i $\mathrm{cd} / \mathrm{icd} 10 \mathrm{~cm} \cdot \mathrm{htm}$

[26] Wright B, O’Shea AM, Ayyagari P, et al. Observation Rates At Veterans' Hospitals More Than Doubled During 2005-13, Similar To Medicare Trends. Health Aff (Millwood). Oct 2015; 34(10): 17301737. PMid: 26438750. https://doi.org/10.1377/hlthaff. 2014.1474 